\title{
Attitude towards girl's feticide among early adulthood and middle age respondents
}

\author{
MEENAKSHI SINGH, RASHMI KUSHWAHA AND ANJALI SAXENA
}

Received: 09.05.2017; Revised: 07.10.2017; Accepted: 21.10.2017

See end of the paper for authors' affiliations MEENAKSHI SINGH Institute of Home Science, Bundelkhand University, JHANSI (U.P.) INDIA Email : singhmeenu71@gmail. com
ABSTRACT : The phenomenon of female feticide in India is not new, where female embryos or fetuses are selectively eliminated after pre-natal sex determination, thus eliminating girl child even before they are born. In Indian society, female feticide has emerged as a burning social problem during the last few years. The present study aims to assess the attitude of both male and female adolescents towards girls' feticide their early adulthood and middle age. For this from Jhansi city, 100 respondents, 50 of early adulthood stage ( 25 male, 25 female) and 50 of middle adulthood stage ( 25 male, 25 female) randomly selected. A structured interview schedule was prepared containing 30 questions to measure the awareness among male and female regarding the female feticide. Results revealed that equal per cent of respondents were in the age group 1840 years and 40-60 years. Maximum per cent of respondents (97\%) were Hindu followed by $3 \%$ respondents Muslim. In early adulthood and middle age group majority of male and female respondents (92 and 90\%) strongly agreed to favorable comments on girl feticide, while for unfavorable comments lesat number of respondents of both sex were in strongly unfavorable category. Attitude of male and female respondents against favorable comments indicated association between sex and attitude in early adulthood i.e. $\chi^{2}=2.2$ but in middle age no association was found $\left(\chi^{2}=36\right)$. On the other hand attitude against unfavorable comments indicated association between sex and attitude in both early adulthood $\left(\chi^{2}=0.156\right)$ and middle age $\left(\chi^{2}=0.581\right)$. Majority of the Hindu respondents both in early adulthood and middle age group strongly agreed to favourable comments on girl feticide. Regarding religion, attitude of Hindu and Muslim against favorable and unfavorable comments indicated association between religion and attitude in both early adulthood and middle age. Results revealed that both sex and religion have association with attitude regarding girl feticide.

KEY WORDS: Attitude, Early and middle adulthood, Girl feticide

- HOW TO CITE THIS PAPER : Singh, Meenakshi, Kushwaha, Rashmi and Saxena, Anjali (2017). Attitude towards girl's feticide among early adulthood and middle age respondents. Asian J. Home Sci., 12 (2) : 453-457, DOI: 10.15740/HAS/AJHS/12.2/453-457. 